\title{
RELATO DE EXPERIÊNCIA NA UTILIZAÇÃO DO PORTFÓLIO NA GRADUAÇÃO EM ENFERMAGEM
}

Rosa Maria Rodrigues ${ }^{1}$

\begin{abstract}
RESUMO: Com o objetivo de avaliar a implementação do portfólio em uma disciplina do Curso de Graduação de Enfermagem após dois anos consecutivos, este estudo tece reflexões sobre a construção de portfólio na formação profissional. Tal experiência foi oriunda dos relatórios dos Seminários Nacionais de Diretrizes para a Educação em Enfermagem. Os aspectos positivos de seu uso focalizam para o desenvolvimento da capacidade crítica do acadêmico, e para a reflexão sobre sua prática profissional; para a capacidade de analisar os problemas e propor soluções e também é um instrumento efetivo na busca de novos conhecimentos. Encontrou-se a repetição de portfólios já apresentados por outros alunos, o estranhamento do método e a dificuldade de autoavaliação. Conclui-se que o tempo e o desenvolvimento em uma única disciplina foram fatores limitantes do seu êxito; o método tem positividades e negatividades, como outras estratégias avaliativas, devendo ser contextualizado quanto a sua utilização.
\end{abstract}

PALAVRAS-CHAVE: Educação superior; Enfermagem; Avaliação educacional.

\section{REPORT OF EXPERIENCE IN USING THE PORTFOLIO IN AN UNDERGRADUATE NURSING COURSE}

ABSTRACT: This study aimed to evaluate the implementation of the portfolio in a course of the Undergraduate Nursing Course after two consecutive years, and brings together reflections about the construction of a portfolio in professional training. Such an experience was based in the reports of the National Seminars of Guidelines for Nursing Education. The positive aspects of its use focus on the development of the student's critical ability, for reflection on his or her professional practice; and on the ability to analyze problems and propose solutions. It is also an effective instrument in seeking new knowledge. Repetition of portfolios already presented by other students, finding the method strange, and difficulty in selfevaluation were all found. It is concluded that the time and the development in a single course were limiting factors for its success; the method has positive and negative aspects, like other evaluative strategies, and must be contextualized for use. KEYWORDS: Higher education; Nursing; Educational evaluation.

\section{RELATO DE EXPERIENCIA EN LA UTILIZACIÓN DEL PORTFOLIO EN LA GRADUACIÓN EN ENFERMERÍA}

RESUMEN: Conla finalidad de evaluar la implementación del portfolio en una asignatura del curso de graduación de enfermería después de dos años consecutivos, este estudio trae reflexiones acerca de la construcción de portfolio en la formación profesional. Tal experiencia se originó de los informes de los Seminarios Nacionales de Diretrices para la Educación en Enfermería. Los aspectos positivos de su uso apuntan para el desarrollo de la capacidad crítica del académico y para la reflexión acerca de su práctica profesional; para la capacidad de analizar los problemas y proponer soluciones, así como es un instrumento efectivo en la búsqueda de nuevos conocimientos. Hubo repetición de portfolios ya presentados por otros alumnos, la no identificación con el método y la dificultad de autoevaluación. Se concluye que el tiempo y el desarrollo en una única asignatura fueron factores limitantes del éxito; el método tiene puntos positivos y negativos, como otras estrategias de evaluación, siendo necesario ser contextualizado cuanto a su utilización.

PALABRAS CLAVE: Educación superior; Enfermería; Evaluación educacional.

${ }^{1}$ Enfermeira. Doutora em Educação. Professora do Curso de Graduação em Enfermagem da Universidade Estadual do Oeste do Paraná.

Autor correspondente:

Recebido: $18 / 08 / 2011$

Rosa Maria Rodrigues

Aprovado: 03/05/2012

Universidade Estadual do Oeste do Paraná

Rua Edi Domingos D'Alla Costa, 489 - 85805-550 - Cascavel-PR-Brasil

E-mail: rmrodri09@gmail.com 


\section{INTRODUÇÃO}

A formação em Enfermagem no Brasil, nos últimos anos e, mais incisivamente, a partir dos anos de 1980 tem se colocado questionamentos acerca da condução do ensino, desde a graduação até a pós-graduação. Neste processo, muitas têm sido as iniciativas de rever, melhorar e aprofundar possibilidades de encaminhar a formação nos aspectos pedagógicos, técnicos, políticos.

Movimentos de mudança podem ser observados em sistematização anterior ${ }^{(1)}$, em que se identificou a preocupação com mudanças curriculares, nas quais os cursos têm se organizado, desde currículos disciplinares tidos como tradicionais, até os currículos integrados. Nestas mudanças, identifica-se a preocupação com os encaminhamentos metodológicos da formação, entre eles, a avaliação que se processa nos cursos. Diante destes movimentos, os sujeitos envolvidos no processo ensino-aprendizagem da Enfermagem, individual ou coletivamente buscam formas de qualificar os processos de formação.

Uma experiência que tem progredido na particularidade da Enfermagem é a estratégia do portfólio, especialmente a partir dos fins dos anos 1990 e início do século XXI, embalada pelas críticas e mudanças oriundas do que se tem chamado de educação para o Século XXI ou educação alicerçada nos pilares da Unesco, expressas no Relatório Jacques Delors, também denominada de educação para o aprender a aprender ${ }^{(2)}$.

Este relato de experiência expõe a utilização da estratégia do portfólio em uma disciplina em dois anos consecutivos, de um curso de graduação em Enfermagem, numa universidade pública que tem entrada anual de 40 alunos. Ele foi usado para avaliação sendo esta a finalidade do portfólio no processo pedagógico. O portfólio, entretanto, visa à superação da avaliação quantitativa, finalística, mensuradora; busca no processo, fazer em conjunto (alunos e professores) a construção do conhecimento. O portfólio pode ser definido como uma

construção feita pelo aluno. Uma coleção de suas produções, as quais apresentam as evidências de sua aprendizagem. É organizado por ele próprio para que ele e o professor, em conjunto, possam acompanhar o seu progresso ${ }^{(3: 207)}$.

Trata-se de estratégia de avaliação visando que os alunos participem da formulação dos objetivos de sua aprendizagem e avaliem seu progresso. "Eles são, portanto, participantes ativos da avaliação, selecionando as melhores amostras de seu trabalho para incluí-las no portfólio"(3:38). Esta estratégia se insere na perspectiva da avaliação formativa definida como aquela que permite a avaliação não só do aluno, mas do professor e também da escola; esta estratégia propõe abandonar a avaliação unilateral, classificatória, punitiva e excludente comprometendo-se com o sucesso e a aprendizagem dos alunos ${ }^{(3)}$.

$\mathrm{Na}$ construção do portfólio é preciso ter claro os objetivos da aprendizagem ${ }^{(3)}$. Neste particular, como condição do trabalho pedagógico docente, tais objetivos, na experiência foram enunciados em todas as aulas e retomados nas aulas seguintes quando havia continuidade no conteúdo em processo de estudo. Além disso, é necessário estabelecer os propósitos gerais e específicos da aprendizagem $^{(3)}$. No que se refere aos gerais, eles eram os constantes no plano de ensino e, nos específicos deixou-se liberdade para que o aluno, pudesse, individualmente elencar o que o movimentaria na direção da apreensão, construção do conhecimento a ser adquirido.

Foram dadas algumas indicações de como confeccionar o material. Uma primeira delas seria basear-se nas anotações processadas durante as aulas desde as indagações/provocações feitas pelo professor, até as emergidas da análise e síntese do aluno. A segunda estratégia indicada foi a leitura de textos base fornecidos para estudo dos conteúdos da disciplina (material didático elaborado pela docente para subsidiar o estudo). E uma terceira indicação foi a inserção de outros dados, para além dos que foram apresentados durante as aulas e das discussões deles decorrentes.

Outro aspecto importante nesta construção é a parada em pontos estratégicos para a análise em grupo do que já foi produzido com apresentação e síntese aos colegas $^{(3)}$. Esta indicação foi etapa negligenciada nesta experiência pela inexistência de tempo suficiente para sua execução.

Outro enfrentamento foi objetivar o processo, diante disso, no primeiro dia de aula foi fornecido um esquema de condução da avaliação que contemplava elementos mínimos, a partir do modelo elaborado por Vilas Boas ${ }^{(3)}$. Construiu-se um quadro que contemplou três colunas: na primeira estavam os descritores utilizados para avaliação (cumpre os propósitos gerais; apresenta análise e justificativa do material incluído; apresenta textos escritos com correção; apresenta dados para além dos trazidos pela professora; apresenta síntese conclusiva; apresenta avaliação final do trabalho; foi construído ao longo do tempo; cumpriu os prazos combinados coletivamente) ${ }^{(3)}$. Na segunda coluna o espaço estava em branco para a autoavaliação do aluno e, na terceira 
coluna, para avaliação do professor. $\mathrm{O}$ resultado desse processo foi exposto em escala de 0-100, de acordo com o regimento acadêmico da instituição, portanto, não houve a possibilidade de atribuir outra menção ao aluno que não a quantificação de seu desempenho.

A perspectiva desta estratégia era que os alunos avançassem para além daquilo que era discutido em sala, com aulas expositivas e abertas à participação. $\mathrm{O}$ incômodo com a estratégia surgiu ao final dos dois anos letivos quando os portfólios foram entregues. $\mathrm{Na}$ sua maioria, tanto no primeiro como no segundo ano em que foi utilizado, constituíam-se em agrupamentos desconexos de tópicos que o professor havia utilizado para conduzir seu pensamento durante as aulas.

Entretanto, o mais desconfortante e desmotivador para o docente, foi constatar a cópia de um portfólio por outro. Essa ocorrência, no entendimento da proposta, destrói sua concepção, que se basearia no crescimento e na maturidade dos alunos e, mais que isso, na possibilidade de desenvolver a interlocução aluno/professor/ conhecimento de forma refletida. Este fato aconteceu nos dois anos consecutivos, não na totalidade dos alunos.

Outro fato limitante da estratégia foi o tempo utilizado com a leitura e comparação entre os portifólios, pois como havia cópias era necessário identificá-las e cruzá-las. Tal fato também colocou por terra os pressupostos da avaliação que deveria deixar de ser punitiva e buscar o diálogo. Como dialogar com um sujeito que burlou as regras? Há possibilidade de superação destas condutas? Assim, tais inquietações levaram à busca de outras experiências, pois era preciso entender os motivos do fracasso da experiência vivenciada.

Foi preciso registrar que alguns alunos entenderam a estratégia e a usaram de forma adequada, mas eles ficaram submersos na névoa dos equívocos, da repetição desconexa do conhecimento e da cópia. Os alunos que evoluíram talvez o fizessem igualmente em outra estratégia tida como tradicional. Assim, este relato visou explorar a utilização do portfólio como estratégia de avaliação do ensino aprendizagem fornecendo elementos para refletir a experiência particular.

\section{A EXPERIÊNCIA DO PORTFÓLIO EM OUTROS CENÁRIOS}

Com a busca de aprofundar a reflexão tomaram-se como fonte documental, relatórios dos Seminários Nacionais de Diretrizes para a Educação em Enfermagem (SENADEN), os quais foram lidos para identificação de trabalhos apresentados que versassem sobre a avaliação por meio do portfólio. Eles foram lidos e sistematizados em uma tabela que continha as seguintes informações: estudo (título e autores); tema; objetivo; amostra/sujeitos; metodologia; técnica de coleta de dados; análise dos dados; conclusão). A análise do material se deu pela quantificação dos estudos e da síntese a respeito de como esta estratégia de avaliação tem sido utilizada, e quais os seus resultados.

Esta sistematização permitiu identificar a temática da avaliação utilizando-se o portfólio no sétimo SENADEN, em 2003 no qual se encontrou dois textos; no oitavo, um; no nono, dois; no décimo, quatro e no décimo primeiro, dois, totalizando 11 trabalhos. O tempo em que surge a discussão permite afirmar que ela é recente e pouco divulgada, em especial no espaço privilegiado para generalização dos conhecimentos sobre as práticas educativas em Enfermagem que é o SENADEN.

Os dados mostram que não é numerosa a ocorrência de trabalhos sobre portfólio, pois este evento tem, em média, 150 a 200 trabalhos inscritos em cada edição. Portanto, quem tem utilizado tal estratégia de avaliação? Identificou-se que se preocupam com novos métodos avaliativos cursos que iniciaram movimentos de mudança de seu processo de formação, notadamente os que adotaram a estrutura de currículo integrado. Os que a utilizam indicam, implícita ou claramente, a concepção de avaliação formativa denominada também de avaliação dialógica.

As positividades do portfólio, a partir dos resumos dos SENADEN, foram apontadas quando a estratégia possibilitava comprometimento e reflexão sobre a prática; diminuição da ansiedade pela avaliação processual; a relação professor/aluno horizontal sendo o aluno instrumentalizado para a tomada de decisão. Ainda, a avaliação formativa e somativa; o reconhecimento pelo aluno da construção de sua aprendizagem e proposição de estratégias de superação dos problemas; melhoria da participação com repercussões nos processos de negociação e comunicação.

Os resumos indicam que a estratégia permitiu a construção da identidade profissional, de uma enfermagem mais crítica e reflexiva; reflexão sobre as práticas desenvolvidas, assegurando a construção do conhecimento profissional e pessoal; estímulo a busca de conhecimentos para voltar à prática buscando sua transformação. Também o portfólio propiciou a autoavaliação e a avaliação formativa; reflexões sobre vivências; estímulo à criatividade; relacionar teoria e prática; capacidade de aceitar críticas; o acompanhamento da própria evolução; desempenhar novos papéis, compartilhar ideias, emoções e posicionamentos; e 
focalizar-se no processo.

Em um relato, de 2008, o portfólio foi utilizado na perspectiva da autoavaliação em disciplina prática. As autoras salientaram que esta é

proporcionada pela construção do portfólio de ensino, [...] um instrumento valioso para a aprendizagem e pode contribuir na formação profissional $^{(4: 615)}$.

As fragilidades encontradas puderam ser exemplificadas na disponibilidade de tempo dos professores/facilitadores para realizar a leitura do portfólio; dificuldade dos estudantes para entenderem o movimento metodológico do instrumento, e por estarem num processo de transição do método tradicional ao método crítico $^{(5)}$.

Percebeu-se um importante investimento físico, intelectual e emocional no desenvolvimento da proposta, que requer maior envolvimento do que os métodos tidos como tradicionais de avaliação. Por outro lado, não dá para afirmar que é um método infalível pois, como outras estratégias tem potencialidades e dificuldades. Em especial, dificuldades referente aos sujeitos envolvidos - os alunos, devido às características e vivências que trazem, e aos docentes pela dificuldade em se adaptar e envolver com novas formas de fazer o que sempre fizeram de um mesmo jeito.

A intervenção nos processos pedagógicos é produzida por, com e para sujeitos em construção. Esta relação é múltipla, complexa e só adquire sentido quando contextualizada. Parece válido "afirmar que não serão procedimentos específicos - de sucesso para alguns que serão procedimentos válidos para todos"(6:25).

\section{CONSIDERAÇÕES FINAIS}

Após observar as potencialidades e fragilidades trazidas pelos autores, questionou-se o que determinou a dificuldade na experiência com a estratégia.

Um primeiro aspecto neste entendimento é o fato de que a experiência envolveu uma disciplina pontual o que pode ter potencializado o fracasso da avaliação, uma vez que ela deveria na perspectiva formativa, voltar-se para a avaliação do aluno, do professor e da escola. Neste aspecto ela é falha pois, o trabalho como um todo não foi levado em consideração.

Os resumos dos SENADEN quase sempre se referiam à inovações curriculares, principalmente aqueles cursos que desenvolvem currículos integrados o que seria outro fator não potencializador da experiência relatada, aplicação pontual em uma disciplina e portanto, não gerando impacto na perspectiva do aluno que continuou sendo avaliado de forma tradicional no restante da série.

Outro aspecto, para o qual não se tem elementos de resposta é o que envolve a pergunta: os alunos têm maturidade para vivenciar processos participativos, não punitivos de avaliação? Na experiência relatada, eles trataram a avaliação pelo portfólio, da mesma forma que tratariam a avaliação através de provas no fim do bimestre. Ou seja, utilizando os mesmos artifícios.

Outro aspecto a se considerar, diz respeito à organização do trabalho pedagógico, pois muitas vezes não potencializa este tipo de atividade, pois o tempo gasto com seu acompanhamento é infinitamente maior do que normalmente se gastaria com uma estratégia "tradicional" de avaliação. É possível tentar uma ou duas vezes, mas o desgaste físico e emocional do docente (principalmente quando se identifica as cópias) supera o otimismo em relação às potencialidades ou perspectivas de resgate do sujeito. Quem é esse sujeito? Parece que há uma carência de consenso acerca de quem seja o novo homem que adentra ao espaço universitário sendo esta uma questão urgente. De que ele é fruto? Há espaço para estabelecerem-se diálogos críticos e reflexivos? Para o estabelecimento de relações respeitosas, solidárias? Ou adentra-se ao auge das relações individualizadas? Como são os sujeitos da relação pedagógica (professor e aluno)? Como avaliar neste contexto? Estas questões parecem carecer de reflexões, pois as boas intenções parecem esbarrar nas peculiaridades da sociabilidade que se construiu nos tempos pós-modernos, marcados pelo individualismo, pela banalização e efemeridade das relações, dentre elas, a relação professor/aluno/conhecimento.

\section{REFERÊNCIAS}

1. Backes A, Silva RPG, Rodrigues RM. Reformas curriculares no ensino de graduação em enfermagem: processos, tendências e desafios. Cienc. cuid. saude. 2007;2(6):223-30.

2. Duarte N. Vigotski e o "aprender a aprender": crítica às apropriações neoliberais e pós-modernas da teoria vigotskiana. $2^{\mathrm{a}}$ ed rev ampl. Campinas: Autores Associados; 2001.

3. Vilas Boas MBF. Portfólio, avaliação e trabalho pedagógico. $4^{\text {a }}$ ed. Campinas: Papirus; 2007.

4. Krozeta K, Meier MJ, Danski RD. A auto avaliação:

Cogitare Enferm. 2012 Out/Dez; 17(4):779-83 
uma possibilidade de mudança na formação profissional. Cogitare enferm. 2008;13(4):612-5

5. Peres CRFB, Takeda E, Chirelli MQ, Dadalti MRM. Unidade de prática profissional 1: visão dos docentes sobre a aplicação do portfólio reflexivo como instrumento de avaliação. In: $9^{\circ}$ Seminário Nacional de Diretrizes para a Educação em Enfermagem; 2005. p. 87; Natal, Brasil. Natal; 2005.

6. Vieira, ML; De Sordi, MRL. Possibilidades e limites do uso do portfolio no trabalho pedagógico no ensino superior. E-curriculum. 2012;8(1):1-27. 